\title{
SOBRE ESTÉTICA Y POÉTICA CERNUDIANAS. UNAS NOTAS DESDE LA LECTURA DE PIERRE REVERDY
}

\author{
José Miguel Serrano de LA Torre \\ Universidad de Málaga
}

\section{MOTIVACIÓN, DESCUBRIMIENTO, VALORACIÓN}

En retrospectiva tan amplia que altera los límites de la cronología hasta conceder la validez y la autoridad de lo mítico y lo atemporal, Homero, reconociendo y reivindicando la sabiduría del más viejo frente a la ligereza de juicio del joven, declaraba a través de éste, Antíloco: «Sabes cómo resultan los excesos de un hombre joven: / rauda es la imaginación, pero poco sutil el ingenio» ${ }^{2}$. Desde luego, la diferencia que signa la capacidad razonadora del mayor no se debe tanto a esta simple superación temporal como al hecho de que durante el transcurso cronológico ha ido adquiriendo, sustentado en su trayectoria vital, un mayor número de experiencias. Desde este punto de vista, son inherentes al concepto mismo de 'experiencia' su carácter histórico, de naturaleza dialéctica, y su carácter abierto, frente a la consideración diltheyana y del conocimiento científico en general, que pretende objetivar cada acontecimiento alienándolo de su condicionante cronológico: «Lo dicho nunca posee su verdad en sí mismo, sino que remite, hacia atrás y hacia adelante, a lo no dicho. Toda declaración está motivada» ${ }^{2}$. Esto conduce, asimismo, a la consecuencia epistemológica más radical del pensamiento moderno, a su vez implicada en la deductiva aristotélica, «la producción genética del saber se realiza mediante un desarrollo simultáneo de la conciencia y su objeto. La conciencia que ha superado su objeto se convierte de esta forma en una conciencia nueva y más rica» ${ }^{3}$. Por último,

\footnotetext{
${ }^{1}$ Homero, Iliada, trad., pról. y notas de E. Crespo Güemes, Madrid, Gredos, 1991, XXIII, 589-590.

${ }^{2}$ H. G. Gadamer, Verdad y método, Salamanca, Sígueme, 1992, II, p. 151.

${ }^{3}$ L. E. DE SANTIAGo Guervós, Tradición, lenguaje y praxis en la hermenéutica de H. G. Gadamer, Málaga, Universidad, 1987, p. 45.
}

Rlit, LXV, 129 (2003), 167-197 
para completar una definición básica pero global, debe admitirse que «la experiencia auténtica es aquella en la que el hombre se hace consciente de su finitud» ${ }^{4}$.

De otra parte, la fenoménica experiencial no se entiende sino como sucesos que la arbitrariedad, la casuística a la que está sometido el individuo, le ha deparado por destino o por voluntad divina, «la experiencia tiene lugar como un acontecer del que nadie es dueño, no está determinada como tal por el peso específico de una observación, sino que en ella todo viene a ordenarse de una manera realmente impenetrable» (ib., p. 428). Se hace así tan inaprehensible que sólo el cálculo estadístico sobre aquellos acontecimientos a los que el sujeto se ha enfrentado, puede ofrecer una orientación, aunque siempre relativa. Esta actitud consiliar la adquirirá aquel que haya sufrido un mayor número de casos, ya que así poseerá en su bagaje una cantidad más amplia de soluciones que garanticen la solvencia y la finalización airosa de las cuestiones que puedan plantearse. Éstos son los que más han vivido, los más sabios, frente a los jóvenes, a los que han de orientar y de los que deben recibir por ello mismo un profundo respeto, porque de su consejo depende el éxito de las empresas que vayan abordando desde su inexperiencia ${ }^{5}$. De ahí que Menelao responda a Antíloco arguyendo que su error no es producto de su persona, sino de su juventud: «[...] Nada desvariado ni mentecato has sido / nunca, y ahora ha sido la mocedad lo que ha vencido tu juicio» (ib., vv. 603-604). En este sentido, sentencia Aristóteles que «la experiencia [...] ha creado el arte; la inexperiencia marcha a la ventura. El arte comienza, cuando de un gran número de nociones suministradas por la experiencia, se forma una sola concepción general que se aplica a todos los casos semejantes» (ib., p. 36). Por tanto, la advertencia que el mayor profiere hacia los más jóvenes acaba convirtiéndose en un acto de magisterio ${ }^{6}$, porque, como asevera W. Jaeger - para quien los conceptos correspondientes a aquéllos serían la areté descrita por Homero y los individuos de la clase aristocrática, que siempre deben tender hacia aquélla por medio de los exempla propuestos en sus magna opera-, «la educación no es posible sin que se ofrezca al espíritu una imagen del hombre tal como debe ser. [...] Lo fundamental en ella es kalón, es decir, la belleza, en el sentido normativo de la imagen, imagen

\footnotetext{
${ }^{4}$ H. G. GADAMER, op. cit., I, p. 433.

5 ARISTóteles, Metafísica, Madrid, Espasa-Calpe, $1990^{13}$, p. 37: «Sin embargo, el conocimiento y la inteligencia, según la opinión común, son más bien patrimonio del arte que de la experiencia, y los hombres de arte pasan por ser más sabios que los hombres de experiencia, porque la sabiduría está en todos los hombres en razón de su saber. El motivo de esto es que los unos conocen la causa y los otros la ignoran».

${ }^{6} I d$ : «Añádase a esto que el carácter principal de la ciencia consiste en poder ser transmitida por la enseñanza. Y así, según la opinión común, el arte, más que la experiencia, es ciencia; porque los hombres de arte pueden enseñar, y los hombres de experiencia no».
} 
anhelada, del ideal» ${ }^{7}$. Cuando H. Lausberg compara «el curso natural del acontecer» con el «crecimiento de un árbol», asume la proyección del objeto a su máximo esplendor, a su realización plena, como consecución de un estado ideal. Restringiendo considerablemente el concepto de educación de W. Jaeger, H. Lausberg explica la adquisición de la destreza oratoria como la de cualquier otra habilidad humana, partiendo desde una situación de inexperiencia a otra de experiencia gracias a la tyche. La experiencia lograda se desarrolla mediante la mímesis con la seguridad de que ya no hace falta recurrir al azar, pues ya ha sido deducida la techne que conduce necesariamente al ergon. Por tanto, en el magisterio, «la asimilación de la experiencia por parte de los aprendices puede primeramente realizarse mediante la imitación (mímesis, imitatio) concreta de los modelos (parádeigma, exemplum) creados por el maestro» ${ }^{8}$. Finalmente, este prolongado proceso culmina en la adquisición de la areté.

Este vínculo inexcusable entre lo antiguo y lo moderno no deja de ofrecer, sin embargo, una amplia gama de variantes cuando ha sido sometido a tratamiento cultural y literario, porque aunque a veces, en términos positivos, se achaquen las virtudes del uno al otro, configurando ese concurrido tópico del puer/senex ${ }^{9}$, en ocasiones esta conexión favorable puede convertirse en un auténtico conflicto cuando adquiere la forma del rechazo de unos por los otros, y ahí surgen las fuertes polémicas cada vez que en la historia del pensamiento o del arte se ha pretendido acabar con las maneras inmediatamente anteriores ${ }^{10}$.

La argumentación hasta aquí expuesta puede parecer prolija para el caso al que queremos llegar, mas, de cualquier forma, cumple por ello sobradamente la función explicativa que nos interesa. A su vez, apunta a una consideración mayor -imposible de atender en estas páginas - sobre la translatio cultural y poética que determina la configuración de una poesía que ha sabido, desde su concepción del arte literario y en el ejercicio de su escritura, insertarse con derecho propio en la tradición literaria, instituyéndose en nuevo eslabón de una cadena tan compleja y diversificada como es la de la historia del arte. En este sentido, y centrándonos en el objeto de estas líneas, Pedro Salinas ha desempeñado con respecto a la mayoría

\footnotetext{
7 W. JAEGER, Paideia: los ideales de la cultura griega, Madrid, FCE, 1996 [1933], p. 19.

${ }^{8} \mathrm{H}$. LAUSBERG, Manual de retórica literaria. Fundamentos de una ciencia de la literatura, Madrid, Gredos, 1990 [1966], p. 60.

${ }^{9}$ Este motivo es ampliamente tratado en sus distintas variantes por el ya clásico E. R. CURTIUS, Literatura europea y Edad Media latina, 2 vols., Madrid, FCE, 1988 [1948], I, pp. 149-159.

${ }_{10}$ A esta cuestión dedica un gran y siempre revelador espacio, G. HIGUET, La tradición clásica. Influencias griegas y romanas en la literatura occidental, 2 vols., México D.F., FCE, 1996 [1949], en los capítulos «La querella de antiguos y modernos», I, pp. 411-449, y «El Parnaso y el Anticristo», II, pp. 218-258.
} 
de poetas de la llamada Generación del $27^{11}$, sobre todo, la función del maestro en la dualidad antes reseñada, aunque no se puede considerar que la desarrollara por erigirse en modelo poético ${ }^{12}$, más que en cuanto se permite el consejo y la sugerencia. Quien probablemente ofrezca con mayor precisión el detalle de este vínculo es Rafael Alberti:

Siempre quise a Salinas y lo respeté como lo que realmente era: un hermano mayor de generación. (Así, también, Guillén). Su severa verdad poética, aunque tan distante de la mía o de la de otros poetas del sur, siempre me atrajo por lo humana y tranquila, reveladora, aun en sus más exaltados instantes, de un reposado corazón sin grandes sobresaltos ni amarguras ${ }^{13}$.

Un indicio de ese respeto común del que era objeto Salinas puede verificarse en el hecho de que «don Pedro le llamaban todos, aunque lo tuteasen» (ib., p. 212), circunstancia que unos emplean para usufructo personal ${ }^{14}$, y de la que otros reniégan pudorosamente ${ }^{15}$. J. Guillén alude a esta anécdota cuando rememora que «en Sevilla comenzaron a llamarle don Pedro» ${ }^{16}$, extremo que testimonia el mismo poeta de Valladolid al reproducir solicitud de un admirador de Salinas: " $¡ Y$ cuánto recuerdo en estos días a nuestro amigo don Pedro!"» ${ }^{17}$.

$\mathrm{Su}$ consejo ofrece cobertura al mismo Lorca cuando le cuestiona la forma en que habían de publicarse sus tres primeros libros, si juntos o separados, a lo que «la respuesta del último es tajante: deben aparecer separadamente» ${ }^{18}$, y no puede obviarse que desde Guillén a Emilio Pra-

\footnotetext{
$"$ Sin entrar en las arduas polémicas suscitadas por el empleo historiográfico de este término, me refiero «al Veintisiete como a aquellos poetas que, en conjunción o en colisión con otros coetáneos, desarrollaron las potencialidades de los códigos vanguardistas de moda en los años 20 y 30 de acuerdo con sus propias trayectorias métrico-estilísticas individuales» (G. GARROTE BERNAL, introd., selección, notas y propuestas didácticas, Trayectorias poéticas del Veintisiete, Madrid, Magisterio, 1994, p. 15).

12 Precisamente, el hecho de que no existiera una personalidad declarada que sustentase el liderazgo entre los poetas del 27 ha sido reproche común a la hora de examinar el ajuste de tal conjunto de poetas a la definición generacional tan traída y llevada que en su momento (1930) proporcionó Petersen.

${ }_{13}$ R. AlBerTI, La arboleda perdida, Barcelona, Seix Barral, 1989, I, p. 213.

14 D. Alonso, «Con Pedro Salinas», en A. P. Debicki (ed.), Pedro Salinas, Madrid, Taurus, 1976, p. 54n; Clavileño, 11 (1951): «Ahora, diciembre de 1951, muerto mi amigo, debo aclarar que esto del "don" era una broma mutua. Nos hemos dompedreado y dondamaseado a lo largo de casi treinta años de amistad».

15 J. GUILlÉN, «Federico en persona», en Federico GARCÍA LORCA, Obras completas, ed. de A. del Hoyo, Madrid, Aguilar, 198622, I, p. XXXIII: "Y Salinas, nada don Pedro, con su humor madrileñísimo, humano como ninguno; a todos entiende y con todos se las entiende muy bien».

16 J. GuilléN, «Elogio de Pedro Salinas», en P. DEBICKI (ed.), op. cit., pp. 25-33; p. 31.

17 P. SAlinas y J. Guillén, Correspondencia (1923-1951), ed., introd. y notas de A. Soria Olmedo, Barcelona, Tusquets, 1992, p. 199.

${ }_{18}$ I. GiBSON, Federico García Lorca I. De Fuentevaqueros a Nueva York (1898-1929), Barcelona, Grijalbo, $1988^{4}$, p. 456.
} 
dos, pasando por Rafael Alberti y Luis Cernuda, todos le dedican a Salinas sus libros. Aun sin rendir una obediencia ciega a los esquemas generacionales, hay que reconocer que «mayores eran Pedro Salinas, Jorge Guillén, Gerardo Diego: del 91, del 93, del 96» ${ }^{19}$, hecho en el que abunda la crítica al establecer criterios de prioridad al menos cronológica, de modo que «viniendo a coincidir con ellos, Jorge Guillén primero y, un poco más tarde, Gerardo Diego y Dámaso Alonso, encabezará la nueva generación poética [de poetas y críticos] surgida entre 1920 y $1925[\ldots]{ }^{20}$. Esta circunstancia, en connivencia con parámetros de orden estético, conduce a que «en todo caso, no puede ignorarse que la poesía de Salinas significó, en cierto momento generacional [el de los años treinta], una voz simbólica, un signo lírico muy de una cierta sensibilidad que se dio, fruto nuevo de un tiempo intelectual y poético, en esos años» ${ }^{21}$. El mismo Salinas, consciente o no de ello, siente esa misión de caudillaje y guía que el destino le ha impuesto tácitamente, de ahí que una vez enumerados los espacios por los que fue ejerciendo su actividad profesoral, no sólo advierta el paralelismo con Jorge Guillén por verse en esos mismos lugares, sino que reconoce que «a todos esos sitios llegué yo el primero, como el mayor, que va a enterarse de si las cosas están bien para avisar que puede venir el más pequeño; y luego, cuando yo me iba - eso es lo malo- venía él a vivirlo como lo había vivido yo, cada vez más pasmados por esta firmeza de destinos paralelos» ${ }^{22}$.

En palabras que con el paso del tiempo girarán hacia sentidos radicalmente opuestos, Cernuda contribuye de forma clara al reconocimiento que merecidamente tributa a Salinas el conjunto de su generación poética, por eso cuando habla de Presagios y Seguro azar «no quiero callar la generosidad de su autor. Entre nosotros pocos escritores jóvenes habrá que no deban a esta generosidad, tan poco frecuente en el ambiente literario, algún favor importante o decisivo para un espíritu joven que busca su camino. Quien acude a él halla siempre, por lo menos, una palabra cordial, un gesto de estímulo» ${ }^{23}$. Promotor de la publicación primera de Perfil del Aire, revela en este hecho su padrinazgo, a la vez que delata su capacidad para promocionar a estos poetas incipientes del 27; un contexto que a veces delata prácticas no demasiado honorables:

19 J. GUILLÉN, «Lenguaje de poema, una generación», en Lenguaje y poesía, Madrid, Alianza, 1983, p. 184

${ }^{20}$ Á. DEL Río, «El poeta Pedro Salinas», en A. P. DEBICKI (ed.), op. cit., p. 15; Revista Hispánica Moderna, VII, 1941.

${ }^{21}$ J. L. CANO, «La poesía de Pedro Salinas», en La poesía de la generación del 27, Barcelona, Labor, 1986, pp. 59-60.

${ }^{22}$ P. SAlinAS, «Nueve o diez poetas», en Ensayos completos, Madrid, Taurus, 1983, III, pp. 308-321; p. 311.

${ }^{23}$ L. Cennuda, «Pedro Salinas y su poesía» [1929], en Obra completa III. Prosa II, ed. de D. Harris y L. Maristany, Madrid, Siruela, 1994, pp. 18-21; pp. 20-21. 
Pero luego, en la prosa epistolar el disgusto: la cuestión Cernuda. Porque es imposible ya evitar la salida de Perfil del aire y eso a ti te contraría un poco, por lo que veo. Es imposible evitarlo por razones materiales, esto es que ya está entregado y anunciado y Cernuda con una ilusión obsesiva por verlo hecho, y por razones psicológicas, éstas son la reserva de Cernuda, su testarudez, lo difícil que sería cualquier insinuación dilatoria por mi parte. $\mathrm{Y}$ yo estoy verdaderamente desesperado porque me considero el culpable de todo. Si Cernuda hace versos es casi por mi influencia, si te leyó a ti y se entusiasmó con tu lenguaje fue por mí, y si ha publicado en alguna parte por mí ha sido también. $\mathrm{Y}$ yo, hacedor inconsciente, estaba formando una criatura poética a tu semejanza literaria, y que hoy te molestes con el anuncio de su libro. Comprenderás mi disgusto. Aunque por otra parte no tienes razón alguna para desear con fuerza que no salga ese librito. Tú sabes, y no soy yo quien te lo va a decir, la distancia que va en extensión y en intensidad, de tu poesía a la de Cernuda. Y todo el mundo sabe quién eres tú, qué edad poética tienes, y cuál es tu familia lírica. Es decir, el librito es, de Cernuda casi un éxito tuyo [sic], una conquista antes de salir a batalla. [...] Pero si tu contrariedad persiste, yo, culpable de todo, estoy dispuesto a matar a Cernuda y a comprar la edición íntegra de su obra póstuma para regalarla a una biblioteca pública y evitar así que se lea ${ }^{24}$.

Cita amplia pero reveladora no sólo de esa conducción de autores primerizos, sino de la conciencia y la asunción de esta actividad, cuyo ejercicio no está exento de las desviaciones a que toda relación compleja está abocada. De cualquier forma, habría que apuntar brevemente la naturaleza de esa orientación tan aludida. La formación del propio Salinas determina a su vez, como es lógico, las recomendaciones que dirige a los demás, especialmente a los que empiezan. En este sentido, cabe advertir «la relevante ascendencia futuristaultraísta que existe en los versos de Salinas, especialmente en los de sus primeros libros» ${ }^{25}$, lo que lo sitúa con Gerardo Diego como el autor más versátil desde el punto de vista de la adopción de los distintos estilos que rápidamente se van sucediendo en su época. Frente al resto de sus coetáneos del 27, Salinas es ya un iniciado que fundamenta su acervo poético en un sólido conocimiento de la literatura francesa. Resulta interesante a nuestro propósito respecto a los consejos que Salinas proferirá a Cernuda, reiterando historias y confirmando paralelismos, que «Canedo le inició en el conocimiento de la poesía francesa moderna, cuya atracción sentirá Salinas como consecuencia necesaria de un gusto formado en la lectura de los maestros modernistas. Este contacto inicial con las letras francesas se intensifica hasta dejar una huella permanente en los tres años (1914-1917) que Salinas pasa como Lector de Español en la Sorbona» ${ }^{26}$.

\footnotetext{
${ }^{24}$ Carta sin fechar de P. Salinas a J. Guillén, que según el editor de la misma «debe ser de comienzos de 1927, anterior en todo caso al mes de abril», mes en el que aparece la editio princeps de Perfil del Aire; en P. SAlinas y J. GuILlÉn, op. cit., pp. 69-70.

${ }^{25}$ P. AULlÓN DE HARO, La poesía en el siglo XX (hasta 1939), Madrid, Taurus, 1989, p. 186.

26 Á. DEL Río, op. cit., pp. 19-20; sobre las lecturas francesas de Pedro Salinas, resulta revelador el estudio de B. Gicovate, «Pedro Salinas y Marcel Proust: seducción y retorno», Asomante, XVI (1960), pp. 7-16.
} 
La recomendación de Pedro Salinas sobre la conveniencia de la lectura de la poesía francesa para su maduración como creador, efectivamente supuso la causa principal por la que Luis Cernuda se introdujo en la poesía de Pierre Reverdy. Sin duda, este nombre no podía menos que resonar en el entorno literario de la época por las intensas polémicas suscitadas en relación con las dependencias que la poética creacionista de Vicente Huidobro parecía sostener con la cubista, desde que «en 1920 el exoticista guatemalteco Gómez Carrillo actuó de difusor del Cubismo» ${ }^{27}$ en conjunción con Lasso de la Vega y Guillermo de Torre ${ }^{28}$. La arribada en 1910 de Reverdy, desde su Narbonne natal, a la Montmartre parisina, determina toda su trayectoria artística. Allí, de la mano de Max Jacob entabla relación con el mundo artístico más vivo del momento: Gris, Picasso, Braque, Laurens, Matisse, Leger, Apollinaire. A la vez que se establece esta comunicación cotidiana, Reverdy publica en 1915 su primer libro de poemas, Les poèmes en prose, labor que se continúa en Quelques poèmes (1916), La Lucarne ovale (1916), Les Ardoises du Toit (1918), Les Jockeys camouflés (1918), La Guitare endormie (1919), Étoiles peintes (1921), Coeur de Chêne (1921), Cravates de Chanvre (1922), Grande nature (1925), Ecumes de la Mer (1925). Excepto los dos últimos libros, el resto fue reunido y editado bajo el título de Les épaves du ciel, en 1922. No escapó a su escritura el género novelístico, primero en L'Imperméable, que le conduce a la redacción de La Peau de l'homme (1924), tras Le.Voleur de Talan (1917). Además, vinculada estrechamente a su faceta de ensayista hay que subrayar «un aspecto que le pertenece de manera personal y que surge tanto de su ser moral como de su intelecto: la preocupación por el rigor en la práctica del análisis, unida a su inquietud por la precisión — su palabra preferida- a la hora de expresar una idea» ${ }^{29}$; en este sentido, cabe destacar sus ensayos sobre arte y poética en Sur le cubisme, Essai d'esthétique littéraire, L'Image, sin olvidar especialmente Le Gant de Crin (1927), Le livre de mon bord (1948) y En Vrac (1956), entre otros, compendiados y traducidos en nutrida selección en Escritos para una estética (1977) por Monte Ávila Editores, configurada a su vez por las autorizadas ediciones de los ensayos reverdyanos realizadas por Etienne-Alain Hubert ${ }^{30}$. Esta preocupa-

${ }^{27}$ P. AUllón DE HARO, op. cit., p. 158; del mismo, esclarecen esta cuestión sus estudios, «La Teoría poética del Creacionismo», Cuadernos Hispanoamericanos, 427 (1986), pp. 49-73, y «La transcendencia de la Poesía y el Pensamiento poético de Vicente Huidobro», Revista de Occidente, 86-87 (1988), pp. 41-58; para esta cuestión véase también el colectivo de R. DE COSTA (ed.), Vicente Huidobro y el Creacionismo, Madrid, Taurus, 1975.

${ }^{28}$ G. DE TORRE, «Los verdaderos antecedentes líricos del creacionismo en Vicente Huidobro. Un genial e incógnito precursor uruguayo: Julio Herrera Reissig», Alfar (1923).

${ }^{29}$ E.-A. HubERT, «Reverdy y Nord-Sud», Hora de Poesía, 88-90 (1993), pp. 136-137.

${ }^{30}$ Cette émotion appelée poésie: Écrits sur la poésie (1932-1960), Flammarion, 1974, y «Nord-Sud». Self Defence et autres écrits sur l'art et la poésie (1917-1926), Flam- 
ción estética constituye el germen que motivará la creación por parte de Reverdy de la revista Nord-Sud (1916-1926):

1916 - señaló el momento a partir del cual podía hablarse de estética, y yo lo hice en Nord-Sud porque la misma época alentaba su organización, la confluencia de ideas, porque la fantasía cedía terreno a la necesidad de estructura y porque ese sentimiento se manifestaba en mí con fuerza suficiente como para fundar una revista donde expresar y hacer realidad esta idea ${ }^{31}$.

Una nota importante descuella de sus ensayos, característica de su escritura que puede relacionarse con la admiración cernudiana hacia los aspectos determinados que destaca en su poesía, y es que «nada que ver con las inflamadas redundancias de los manifiestos futuristas ni con la fraseología del simbolismo agonizante o las escuelas que se habían multiplicado en los años que preceden a la guerra del 14. A medida que avanzan los números de la revista, observamos incluso que esta prosa de ideas gana en concisión y brillantez, orientándose hacia una composición en párrafos cortos que no necesitan recurrir a transiciones para concatenarse rigurosamente; el pensamiento tiende a cristalizarse en formulaciones gnómicas y definiciones que anuncian Self Defence. Estos textos prueban que anima al autor un amor por la claridad que podría calificarse de clásico» (ib., p. 137).

En Historial de un libro, de 1959, el propio Cernuda afirma que «Salinas me indicó la necesidad de que leyera también a los poetas franceses, de que aprendiera una lengua extranjera» ${ }^{32}$. Esta indicación la realiza Salinas al conocer al poeta sevillano, cuando éste acaba de finalizar sus estudios de Derecho en $1924^{33}$. Es más, la primera vez que Cernuda habla de Reverdy en sus ensayos, lo hace en un artículo sobre la obra de Salinas, «Pedro Salinas y su poesía», publicado en 1929, en los siguientes términos:

marion, 1975. Para un análisis detallado de la obra de P. Reverdy, si bien su obra viene siendo algo más concurrida por la crítica, siguen resultando de primer orden los estudios de M. Guiney, La poésie de Pierre Reverdy, Ginebra, 1966; J. P. Richard, Onze études sur la poésie moderne, Paris, 1964, y AA. VV., Hommage à Pierre Reverdy, Paris, 1962.

${ }^{31}$ Citado por E.-A. HUBERT, op. cit., p. 135.

${ }^{32}$ L. Cernuda, Historial de un libro, Papeles de Son Armadans, XXXV (1959), pp. 121-172, versión primera pero ampliamente censurada; texto crítico final, que seguimos, en Poesía y Literatura, Obra completa, II. Prosa I, ed. de D. Harris y L. Maristany, Madrid, Siruela, 1994, p. 627.

${ }^{33}$ En este sentido, recuerda el mismo P. SAlinAs, «Nueve o diez poetas», op. cit., III, p. 318: «Pero él era alumno oficial de mi clase de Literatura; mi año primero de enseñanza. Los dos novicios, él en su papel, yo en el mío. Y no le conocí, y se estuvo cerca de un año un profesor - iy de Literatura! - delante del poeta más fino, más delicado, más elegante que le nació a Sevilla, después de Bécquer, sin saberlo». 
Al decir que Presagios ofrece ya totalmente la poesía de un poeta quiero indicar algo esencial en Salinas, que es de esos poetas, como Reverdy, por ejemplo, cuyo primer libro desliza ya el contorno vívido de su definitiva poesía ${ }^{34}$.

Habrá que esperar hasta 1954 para asistir a un nuevo juicio cernudiano sobre Reverdy. Esta vez será en su artículo «El Crítico, el Amigo y el Poeta», donde lo trata por primera vez bajo aspectos que atañen a su propia formación:

- [...] No, el poeta en cuestión, de quien Cernuda aprendió ascetismo poético, es Pierre Reverdy ${ }^{35}$.

Si en la primera cita destaca del poeta francés la concentración poética presente en su primer libro y la compara con el mismo proceder saliniano, en la segunda resalta un rasgo que, en consonancia con el anterior, implica una revelación sobre su propia poética. En definitiva, ambas giran respecto a un mismo criterio elocutivo: la expresión llana que él vio enunciada en Wordsworth - "imitar y, en lo posible, adoptar el lenguaje natural de los hombres"» ${ }^{36}$-, que se irá convirtiendo con el desarrollo de su obra en una de sus insignias poéticas más importantes. Las raíces de esta postura subyacen a las pretensiones programáticas de los movimentos de vanguardia y a la misma «poesía pura», y se pueden hallar en «ese momento incierto, a finales del siglo XVIII, cuando, como ocurre con la poesía de las demás lenguas modernas, el neoclasicismo cede al romanticismo y ambas direcciones, extrañamente, parecen coexistir en algunos poetas, engendrando un lirismo que no es clásico ni tampoco romántico, sino moderno, como ocurre con la poesía de Blake, de Hölderlin, de Leopardi, de Nerval, de Pushkin, época que entre nosotros, por desgracia, no puede cifrarse en nombre alguno ni obra alguna de poeta» ${ }^{37}$.

En este orden de cosas, Cernuda sólo puede salvar la calidad del pensamiento poético de Ramón de Campoamor, muy distante de la expresión de su propio verso. A él se debe «haber desterrado de nuestra poesía el lenguaje preconcebidamente poético» (ib., p. 85), en el sentido de «haber desnudado el lenguaje de todo el oropel viejo, de toda la fraseología falsa que lo ataba» (ib., p. 87); si bien, «al intentar darle expresión poética a lo que había percibido en la realidad de su tiempo y de su país, fracasó» (ib., p. 83). Como Campoamor, Cernuda es consciente de la necesidad de reno-

${ }^{34}$ L. CERnUdA, «Pedro Salinas y su poesía», Revista de Occidente, XXV (1929), pp. 251-254; si bien citamos por Obra completa, III. Prosa II, op. cit., p. 19.

${ }^{35}$ L. CERnUdA, «El Crítico, el Amigo y el Poeta. Diálogo ejemplar», Orígenes, 35 (1954), pp. 18-30; en Poesía y Literatura, Obra completa, II. Prosa I, op. cit., p. 619.

${ }^{36}$ L. Cernuda, Pensamiento poético en la lírica inglesa, México, Imprenta Universitaria, 1958; en Obra completa, II. Prosa I, op. cit., p. 295.

${ }^{37}$ L. CERnuda, Estudios sobre poesía española contemporánea, Madrid-Bogotá, Guadarrama, 1957; en Obra completa, II. Prosa I, op. cit., p. 76. 
vación de que adolece la poesía española desde el siglo XVIII, pero también de la insuficiencia de los intentos llevados a cabo - exceptuados Gustavo Adolfo Bécquer y Rosalía de Castro, prácticamente ignorados por sus contemporáneos- hasta la transición finisecular entre los siglos XIX y $\mathrm{XX}$, al arrastrar hasta esas fechas y promover y cultivar una poesía generada a partir de lo que G. Siebenmann ha denominado «el lastre de la tradición oratoria» ${ }^{38}$, cifrado en determinado "gusto nacional: nos referimos concretamente a la rara preferencia - $\mathrm{O}$ al menos mayor tolerancia- entre los españoles, en comparación con otros pueblos, por todo lo sonoro, hiperbólico o efectista» (ib., p. 23). Se trata de una estética en la que «el "fortissimo" y la conducta más gesticulante que eficazmente expresiva saltan a la vista una y otra vez» (ib., pp. 26-27). Muy relacionada con esta poética se encuentra la facultad del ingenio; al hablar de Gómez de la Serna y de los procedimientos que sustentan a la greguería, Cernuda expone que «su obra se halla, por tanto, dentro de las fronteras del temperamento literario español, que con excepciones contadas fue siempre enemigo de indagar lo que pudiera haber tras de nuestra realidad inmediata, de una parte, y de otra (para compensar su falta de imaginación), muy dado a los juegos del ingenio con la palabra. Porque nuestro ingenio sólo se mueve entre las cuatro esquinas de la realidad, preocupado únicamente por el efecto brillante de las conexiones que establece entre los elementos más dispares de ella. De ahí su variedad y a la larga su tristeza; no en balde el fúnebre Quevedo es nuestro ingenio máximo» ${ }^{39}$.

Este desvío estético, aparte su connaturalidad, se ha visto apoyado por «la cesación de todo contacto vivo con la poesía del mundo clásico, latina y helénica ${ }^{40}$, y de la anulación de cualquier vínculo con «la poesía italiana renacentista, aunque dicha falta podía compensarla la lectura de poetas de otras lenguas; por desgracia, ha sido la lectura de poetas franceses la que con frecuencia reemplazó a los italianos. Y como los defectos de la poesía francesa van en el mismo sentido que los de la nuestra, el resultado ha sido poco feliz casi siempre; aparte de que Francia, con raras excepciones, es país pobre en poetas» (ib., p. 81).

En 1957 vuelve a aparecer la figura de Reverdy, pero esta vez en relación con una polémica de carácter más general, la de la primacía en la invención de la escritura creacionista. Pese a que intenta equilibrar las dos corrientes enconadas en el conflicto, no puede evitar decantarse por una de ellas, esto es, por Reverdy:

\footnotetext{
${ }^{38}$ G. Siebenmann, Los estilos poéticos en España desde 1900, Madrid, Gredos, 1973, p. 23 .

${ }^{39}$ L. CERnUdA, «Gómez de la Serna y la generación poética de 1925» [1955], Estudios, op. cit., pp. 172-180; p. 175.

${ }^{40}$ L. CERnUdA, Estudios, op. cit., p. 80.
} 
Mas por lo que respecta a esta generación que estudiamos también debemos conectar el superrealismo, por las razones que luego diremos, con otro movimiento literario anterior, cuyo origen lo mismo pudo ser francés que hispanoamericano; el creacionismo. Dejemos, sin embargo, a un lado la cuestión de sus orígenes; es decir, si nace en los versos de Pierre Reverdy (cuya obra es antecedente de la de los poetas superrealistas franceses) o en la del chileno Vicente Huidobro; aunque sí convenga recordar que el nombre de creacionismo designa exclusivamente un movimiento poético hispano-americano y no tiene aplicación en la poesía francesa. Huidobro vive en Francia largos años, a partir de aquellos anteriores a la guerra de 1914, cuando surge allá un movimiento de renovación poética que representan, entre otros, Apollinaire y Reverdy. Huidobro escribe en francés y en Francia publica sus libros; mas lo probable es que Reverdy nunca leyera a Huidobro, aunque Huidobro sí leyera a Reverdy ${ }^{41}$.

En el mismo lugar, algo más adelante, la toma de partido se convierte en una defensa denodada de su opinión, donde se desliza también esa inclinación suya por un lenguaje llano para la poesía:

Mas si los primeros poemas creacionistas de Huidobro, a semejanza de los que siempre ha escrito Reverdy, eran variaciones sobre temas de la vida diaria $[\ldots] .(I b .$, p. 217)

Pero será en Historial de un libro, donde la reflexión sobre la influencia de Reverdy en su propia poética se manifieste de forma más contundente:

A partir de 1924 había comenzado a escribir los poemitas que aparecerían en Perfil del Aire, mi libro primero. Mas en él, juntamente con la huella de algunos de los poetas que he mencionado, debo indicar la de Pierre Reverdy, cuyo nombre descubrí en un comentario nada favorable a su obra. No es Reverdy poeta hacia el cual haya conservado mucha estimación, pero entonces me ayudaron algunas cualidades suyas, en favor de las cuales estaba yo predispuesto: desnudez, pureza (sea lo que sea lo que esta palabra, tan abusada, suscite hoy en la mente del lector), reticencia. En todo caso es justa su mención aquí, porque la huella de Reverdy, aunque ningún crítico la percibiera, es visible en Perfil del Aire ${ }^{42}$.

En el mismo tono se expresa en el artículo que con motivo de la muerte de Reverdy escribe Cernuda en 1961 bajo el epígrafe de «Recuerdo de Pierre Reverdy» ${ }^{43}$. Hemos de circunstanciar aquí la situación que motivó tal homenaje, aparte la admiración profesada al maestro francés. En «La palabra edificante», Octavio Paz revela la razón de este reconocimiento de forma explícita:

${ }^{41}$ L. CERnUdA, Estudios, op. cit., p. 190. Sobre la polémica suscitada entre Reverdy y Huidobro, ampliamente abordada, véase R. de Costa (ed.), op. cit.

${ }^{42}$ L. CERNUDA, Historial de un libro, op. cit., p. 627.

43 L. CERnUDA, «Recuerdo de Pierre Reverdy», Mercure de France, 1181 (1962), pp. 68-71; en Obra completa II. Prosa I, Poesía y Literatura II, op. cit., pp. 791-794. 
En 1961, el Mercure de France dedicó un número de homenaje a Pierre Reverdy, muerto hacía poco. Pensé que entre los poetas de nuestra lengua, con la excepción de Vicente Huidobro, ninguno había conocido mejor la obra de Reverdy que Luis Cernuda - «su influencia», me confió alguna vez, «fue determinante en mi formación espiritual»- y sugerí a los amigos del Mercure que pidiesen un testimonio al poeta español ${ }^{44}$.

En este punto, vuelve a especificar el lugar donde más visible se hace su influencia, en tanto que «su ejemplo determinó en parte el rumbo de mi primer libro de versos, aparecidos en $1927{ }^{45}$. Se está refiriendo concretamente a Perfil del Aire, publicado en Málaga como cuarto suplemento de la revista Litoral.

El magisterio ejercido sobre Cernuda se justifica también desde otras perspectivas en las páginas del artículo, las cuales son «preciosas no tanto por lo que nos dice sobre Reverdy como por lo que, indirectamente revelan del mismo Cernuda» ${ }^{46}$. Él mismo llega a afirmar que «comprendo que me parecieran entonces justificadas las palabras que, en la Anthologie anónima de Kra, precedían a la selección de Reverdy, diciendo que los jóvenes poetas le escuchaban con respeto igual a aquel con que, los de su tiempo, escucharon a Mallarmé» ${ }^{47}$.

Tras estos reconocimientos, destaca Cernuda en primer lugar la capacidad de Reverdy para asimilar la tradición al tiempo que la somete a un proceso de renovación, rasgo categorial que cualifica el conjunto poemático cernudiano:

${ }^{44}$ Citamos por la primera edición íntegra, en Papeles de Son Armadans, XXXV, CIII (1964), pp. 41-82, p. 41, fielmente recogida en D. HARRIS (ed.), Luis Cernuda, Madrid, Taurus, 1984, pp. 138-160. La versión que figura en Cuadrivio (Barcelona, Seix-Barral, 1991 [1965], p. 115) aparece visiblemente deturpada en relación con la de Papeles. Altera el comienzo del ensayo, diciendo: «En 1961 el Mercure de France dedicó un número de homenaje a Pierre Reverdy, muerto hacía poco.», y elimina la parte del discurso que precisamente nos interesa, de forma que continúa: «[...] hacía poco. Luis Cernuda escribió unas cuantas páginas [...]». La recomendación de O. Paz sobre la conveniencia de que el Mercure solicitara colaboración a Cernuda para el homenaje a Reverdy, alcanza su constatación en carta del poeta sevillano dirigida a Jacobo Muñoz el 24 de octubre de 1961: «Y Octavio Paz (supongo que le conoce, de nombre al menos) me comprometió con amigos suyos franceses, que organizan un homenaje a Pierre Reverdy, a enviar a éstos unas pocas cuartillas», en F. ORTIZ (comp.), Epistolario inédito, Sevilla, Servicio de Publicaciones del Ayuntamiento, 1981, p. 109. Varias referencias más se suman a ésta en otras cartas de Cernuda: «El número de enero último del "Mercure de France", es homenaje a Reverdy, y publica cosa mía» (22 de febrero de 1962, a J. Muñoz; $i b$., p. 115); «En el número de enero pasado del "Mercure de France", dedicado a Pierre Reverdy, puede ver una colaboración mía» (26 de febrero de 1962, a D. Harris; ib., p. 88 ); «Lo de Reverdy ha aparecido en volumen de homenaje al mismo, no más que recortando el número del "Mercure", en formato de libro» (diciembre de 1962, a J. Muñoz; $i b .$, p. 121).

${ }_{45}$ L. CERnUdA, «Recuerdo de Pierre Reverdy», op. cit., p. 792.

46 O. PAZ, op. cit., p. 138.

${ }^{47}$ L. CERnUDA, «Recuerdo de Pierre Reverdy», op. cit., p. 791. 
Pero la aceptación de su tradición no era en Reverdy, naturalmente, mera repetición, pues que al mismo tiempo la renovaba, transmitiéndola igual y distinta a los poetas que venían tras de él. (Id.)

Recuerda Cernuda la lectura que efectuó del poeta francés en la Anthologie des Poètes Français Contemporains, publicada por la editorial Simon Kra en 1924, dando satisfacción a un interés acrecido de que da cuenta así: «Busqué sus libros y leí con sorpresa y admiración Les Épaves du Ciel» (id.), también de 1924.

Mas la poesía de Reverdy le ofrece a Cernuda un elemento de vital importancia para su propia poética: «en ella no veía esa suntuosidad de temas y de expresión que suele parecernos nota característica de la poesía francesa» (ib., p. 792). Este aserto alcanza su más elevada formulación al calificar al poeta francés de «asceta». Aquí entra directamente en juego la cualidad de pureza que Cernuda proyecta sobre el poeta francés:

Al llamar puro a Reverdy no aludo a una pureza química, como aquella de la poesía «pura», con la que tantos nos cansaron y aburrieron entonces. Aludo a una pureza espiritual, ética, de su conciencia como poeta. Lo suntuoso, lo brillante, lo lujosamente inhumano y un tanto hueco en los versos de un poeta «puro» a la moda por aquellos años, no aparece, ni podía aparecer, en los de Reverdy. Porque tras de éstos estaba una conciencia poética admirable, que había renunciado lo mismo al halago superficial de la sociedad como al del mundo visible, aunque sin renunciar por eso [...] a la hermosura del mismo. Sus poemas tienen siempre carne y alma, no son nunca abstracciones. (Id.)

Frente a esta concepción de la poesía, Cernuda esgrime su construcción poemática enfocada hacia la cotidianeidad en los motivos empleados por el maestro francés al explicar que «con unos pocos objetos exteriores, simples y cotidianos [...] levanta Reverdy sus poemas» (ib., pp. 792-793).

En suma, los testimonios traídos a colación delatan observaciones fundamentales que el mismo Cernuda irá descubriendo en escritos posteriores, cifradas, a su vez, en reflexiones sobre la obra de Reverdy y la influencia que ejerció en su escritura. En primer lugar, Cernuda lee a Reverdy en el momento de iniciarse en la escritura poética, y de ahí que el mayor influjo se concentre en su primer libro; en segundo lugar, en la poesía de Reverdy, Cernuda encuentra dos modulaciones creadoras que se irán confirmando con otras lecturas y alcanzarán pautas primordiales de su poética en su obra más madura, como son, de un lado, el empleo de un lenguaje usual, que no vulgar, sin complicaciones mayores para el léxico y la sintaxis, así como el recurso a una temática de la vida cotidiana, y de otro, el reconocimiento de la tradición poética, del magisterio de los poetas precedentes en su doble vertiente de mantenimiento y renovación de la poesía, la literatura, y el arte en general; en tercer y último lugar, la constatación de los dos rasgos del punto anterior en el transcurso poemático cernudiano corre pareja al proceso formativo a que está sometido su pro- 
pio ethos, de forma que estos principios poéticos están en continua interacción con los principios de moralidad en la proyección diacrónica de ambos.

\section{Confluencias textuales}

D. Harris sintetiza y concluye que «la influencia fue determinante porque Reverdy, además de proporcionar a Cernuda materiales temáticos, reveló también una estética y un concepto del lenguaje poético, hacia los cuales experimentó una atracción poderosa» ${ }^{48}$. Reconoce este mismo estudioso que «la afinidad con la poesía de Reverdy se manifiesta más claramente en los poemas melancólicos de Perfil del Aire, aunque las coincidencias con el poeta francés, más que paralelismos directos, son de tono y de ambiente» (ib., p. 63). Resalta también algunos configurantes temáticos, como el de la hostilidad de la ciudad que obliga al poeta a refugiarse en la soledad, el del jardín, lugar en el que se protege del mundo, y especialmente el motivo del cuarto y los muros. Este asedio al que se ve sometido el poeta, y del que hay referencia explícita en «Recuerdo de Pierre Reverdy», sin duda parece inspirado en el poema «Belle étoile» de los Poèmes en Prose (1915) del francés. Dice Cernuda en su escrito de homenaje:

En él [el poema], un hombre que semeja buscar algún refugio, como tantas veces ocurre en los poemas de Reverdy, halla en el campo una puerta, una puerta sola, sin paredes a los lados ni habitación tras de ella, como al fin seguro. En ese personaje adivino al poeta, acosado por algo o en busca de algo, y creyéndose de momento protegido del mundo y contra el mundo, de su terror y de su atracción ${ }^{49}$.

Reverdy había escrito:

J'aurai peut-être perdu la clé, et tout le monde rit autour de moi et chacun me montre une clé énorme pendue à son cou.

Je suis le seul à en rien avoir pour entrer quelque part. Ils ont tous disparu et les portes closes laissent la rue plus triste. Personne. Je frapperai partout.

Des injures jaillissent des fenêtres et je m'éloigne.

Alors un peu plus loin que la ville, au bord d'une rivière et d'un bois, j'ai trouvé une porte. Une simple porte à claire voie et sans serrure. Je me suis mis derrière et, sous la nuit qui n'a pas de fenêtres mais de larges rideaux, entre la forêt et la rivière qui me protègent, j'ai pu dormir ${ }^{50}$.

${ }^{48}$ D. HARris, «Introducción y estudio», en L. Cernuda, Perfil del Aire. Con otras obras olvidadas e inéditas, documentos y epistolario, London, Tamesis Books, 1971, p. 62 .

${ }^{49}$ L. CERNUDA, «Recuerdo», op. cit., p. 793.

${ }^{50}$ P. REverdy, «Belle Étoile», en Les Épaves du Ciel, Paris, Nouvelle Revue Française, s. f.2 [1924], p. 24, edición que seguimos en adelante. 
Una de las formulaciones más ilustrativas del motivo de la habitación en Reverdy la posee este poema, «Lumiere», perteneciente a la serie Étoiles Peintes (1921):

Une petite tache brille entre les paupières qui battent. La chambre est vide et les volets s'ouvrent dans la poussière. C'est le jour qui entre ou quelque souvenir qui fait pleurer tes yeux. Le paysage du mur — l'horizon de derrièreta mémoire en désordre et le ciel plus près d'eux. Il y a des arbres et des nuages, des têtes qui dépassent et des mains blessées par la lumière. Et puis c'est un rideau qui tombe et qui enveloppe toutes ces formes dans la nuit. (Ib., p. 165)

Compárese con este poema cernudiano bajo el significativo título de «Los muros nada más», de Perfil del Aire ${ }^{51}$ :

Los muros nada más.

Yace la vida, inerte,

sin vida, sin ruido,

sin palabras crueles.

La luz, lívida, escapa,

y el cristal ya se afirma

contra la noche incierta

de arrebatadas lluvias.

Alzada, resucita

tal otra vez la casa:
Los tiempos son idénticos, distintas las miradas.

¿He cerrado la puerta? El olvido me abre sus desnudas estancias grises, blancas, sin aire.

Pero nadie suspira. Un llanto entre las manos, sólo. Silencio, nada:

la oscuridad temblando.

El estado de melancolía durante la espera del gozo es un tema recurrente en Reverdy con claros ecos en Perfil del Aire; he aquí un fragmento de «Grandeur nature»:

Je vois enfin le jour à travers les paupières

Les persiennes de la maison se soulèvent

Et battent

Mais le jour où je devais le rencontrer

N'est pas encore venu (Ib., p. 63)

También se convierte en obsesión recurrente la pérdida de la noción de temporalidad que preside el momento del sueño, tal ocurre en «Esprit pesant»:

[...] Les heures sonnent doucement autour de sa tête; il ne les entend pas. De temps en temps un rêve passe comme un nuage où se mêlent les gravures du fond. (Ib., p. 66)

${ }^{51}$ La totalidad de los versos de L. Cernuda citados en este trabajo han sido traídos de: Obra completa I. Poesía completa, ed. de D. Harris y L. Maristany, Madrid, Siruela, 1993. 
En «L'sprit sort» se produce la superación de los muros que rodean al individuo; sin embargo, se trata de una liberación engañosa, pues el nuevo ámbito también se halla limitado por sus paredes correspondientes:

[...] De mes ongles j'ai griffé la paroi et, morceau à morceau, j'ai fait un trou dans le mur de droite. C'était une fenêtre et le soleil qui voulait m'aveugler n'a pas pu m'empêcher de regarder dehors.

C'était la rue mais le palais n'était plus lá. Je connaissais déjà une autre poussière et d'autres murs qui bordaient le trottoir. (Ib., p. 12)

Además de estas semejanzas puntuales, que podrían detallarse y extenderse con otras aproximaciones menos contundentes, conviene tener muy en cuenta el aserto de D. Harris por el que entiende la posición de Reverdy como un «intermediario entre Mallarmé y Cernuda» ${ }^{52}$, al igual que hace T. McMullan en su estudio «Luis Cernuda y la influencia emergente de Pierre Reverdy» ${ }^{53}$. La razón que fundamenta el interés en tal observación no es otro que el de afinar el perfil que conformó la propia personalidad poética del vate sevillano.

Así, la atención a la poesía de Reverdy está en la línea formativa del joven creador, esto es, Mallarmé ha sido leído por Cernuda en virtud de razones precisas de necesidad expresiva, relacionadas con el reclamo saliniano sobre la lectura de los poetas franceses. De entre ellos, «Baudelaire fue el primer poeta francés a quien entonces comencé a leer en su propia lengua y hacia el cual he conservado devoción y admiración vivas. Luego, aunque mi conocimiento de la lengua era aún deficiente, emprendí la lectura de Mallarmé y de Rimbaud; el verso del primero me apareció ya entonces, y nunca dejó de aparecerme así a través de los años, con una hermosura sin igual» ${ }^{54}$.

Diez años antes a estas palabras, en 1948, en su citado ensayo «El Crítico, el Amigo y el Poeta. Diálogo ejemplar», ya había precisado aún más la ascendecia mallarmeana de sus lecturas ${ }^{55}$ :

Precisamente, por Góngora fue a Mallarmé, y por Góngora halló familiar alguna parte de la poesía francesa. (Ib., p. 621)

Por tanto, la lección de los franceses cuenta con un estímulo más, aparte el deparado por Salinas, y es el que proviene de la lectura de los mismos españoles, en concreto de Góngora. No puede resultar extraña esta conducción cuando realmente se suma, entendemos que de forma autónoma, al rescate poético del poeta cordobés realizado por la escuela simbolista, a

${ }^{52}$ D. HARRIS, «Introducción y estudio», op. cit., p. 64.

53 T. MCMULLAN, nota 24, p. 253.

${ }^{54}$ L. CERnUdA, Historial de un libro, op. cit., p. 627.

55 G. CORREA, «Mallarmé y Garcilaso en Cernuda. De Primeras poesías a la "Égloga" y a la "Oda"», Revista de Occidente, 145 (1975), pp. 72-89. 
la que corresponde «la gloria auténtica de haber iniciado - aunque fuera de un modo casi incomprensible y desde luego inconsciente y pintorescoel gusto por Góngora» ${ }^{56}$. El carácter superficial de estos primeros acercamientos quiebra, sin embargo, en un «poeta colocado en una posición excepcional y excelsa dentro del simbolismo: Mallarmé, el cual, sin haber recibido influjo ninguno de Góngora, más aún, sin haberle conocido, muestra en su poesía algunos puntos de extraña coincidencia con el autor de las Soledades» (ib., p. 527).

En consecuencia, el hecho mismo, y hasta cierto punto anecdótico, que conduce a Cernuda desde Góngora a Mallarmé, consiste en la misma circunstancia que a su vez condujo al poeta galo hacia los textos del cordobés. Cernuda se limita a reconocer los rasgos afines de su escritura. Con todo, supone una razón añadida a la hasta aquí argüida sobre el estímulo saliniano.

A su vez, la lectura de Reverdy, si bien provocada por ese mismo acicate, halla su motivación más directa en otra circunstancia bastante alejada de la recomendación de Salinas. Cuando Cernuda va haciendo relación de los poetas que influyeron de forma más ostensible en la redacción de Perfil del Aire, introduce a Reverdy, «cuyo nombre descubrí en un comentario nada favorable a su obra» ${ }^{57}$. Esto indica que el acercamiento a Reverdy se produce a partir del hallazgo particular de su existencia, y no a una indicación ajena, al menos directa. Apunte que no tiene que ser el de Salinas, sino el de la lectura de Mallarmé. Por eso, la afirmación de D. Harris no posee un soporte cronológico fiable, si bien el texto no desautoriza esa posibilidad. De otra parte, el recurso de Cernuda a Reverdy no parece le condujera a Mallarmé, pues incluso por su relato de acontecimientos, la lectura de éste es anterior, y es más, la probabilidad de que Salinas le citara a este autor es muy alta en comparación con la que se desprende respecto a Reverdy.

De cualquier forma, Cernuda acude a uno y otro por un interés particular en la poesía y en su necesidad de aprender el officium, no porque exista o no relación entre ambos autores, sino por una motivación previa de orden paidético. Por todo ello, es lógico pensar y cabe dentro de la mayor coherencia y organicidad la relación de Mallarmé con Reverdy en el seno de la poética cernudiana.

Así se comprueba en el texto de Reverdy perteneciente a «Tout dort», expuesto por D. Harris como testimonio de esta filiación en torno al tema del «interior solitario»:

${ }^{56}$ D. ALONSO, «Góngora y la literatura contemporánea» [1927], en Estudios y ensayos gongorinos, Madrid, Gredos, 19703, pp. 518-566, p. 526. Aquí dedica Alonso un amplio apartado al análisis biblioráfico de los ensayos que han tratado la relación entre Góngora y Mallarmé («Góngora y el simbolismo») destacando de cada uno de ellos los logros más relevantes.

${ }^{57}$ L. CERNUDA, Historial de un libro, op. cit., p. 627. 
L'arbre du soir, l'abat-jour de la lampe et la clef du repos. Tout tremble quand la porte s'ouvre sans éveiller de bruit. Le rayon blanc traverse la fenêtre et inonde la table. Une main avance à travers l'ombre, le rayon, le papier sur la table. C'est pour prendre la lampe, l'arbre au cercle étendu, l'astre chaud qui s'évade. Un souffle emporte tout, étient la flamme et pousse le rayon. Il n'y a plus rien devant les yeux que la nuit noire et le mur qui soutient la maison ${ }^{58}$.

Sin embargo, la crítica ha insistido en una diferencia básica que distancia las formas de poetizar de uno y otro autor. Se trata de la tendencia a la abstracción, a la universalidad conceptual de la poesía de Cernuda frente a la inclinación hacia lo fenoménico y lo físico que se da en Reverdy. Así lo ponen de manifiesto, cada uno por su lado, D. Harris al vislumbrar en Perfil del Aire una intensa proyección hacia lo objetual, para la que se acoge al poeta francés ${ }^{59}$, y T. McMullan al destacar que la «evocación fragmentaria del mundo fenoménico transmite directamente la reacción predominantemente física de Reverdy ante su experiencia. Perfil del aire, por el contrario, es el producto de una sensibilidad esencialmente intelectual. Es quizá por esta razón por lo que hay tanto lenguaje abstracto en la obra temprana de Cernuda mientras que Les Épaves du Ciel contiene relativamente poco» ${ }^{60}$. Esta misma estudiosa menciona la técnica que permite esa mayor objetivación de la experiencia en la poesía según deseaba el propio Cernuda, esto es, el «correlato objetivo» que descubrirá más adelante en T. S. Eliot ${ }^{61}$. Constituye otro rasgo más que alcanzará su asentamiento y su realización poética en cuanto se produzca el encuentro y la fascinada lectura de los poetas ingleses.

No obstante, el estudio de McMullan reviste un especial interés al hacer explícitos muchos de los segmentos intertextuales atomizados en la obra de Cernuda e inspirados en el poeta francés:

${ }^{58}$ P. REVERDY, Les Épaves du Ciel, op. cit., p. 173.

59 D. HARRIS, «Introducción y estudio», op. cit., p. 66: «La huella que Reverdy dejó en la expresión de Perfil del aire, reforzando la tendencia hacia la sencillez, es más notable en los poemas donde Cernuda emplea objetos o fenómenos cotidianos del mundo que le circundaba [...] para transcribir su reacción frente a aquel mundo. [...] hay en los poemas de Cernuda la misma parquedad de elementos, la misma visión directa del mundo, e incluso el mismo deseo de confundirse con el corazón del mundo».

${ }^{60}$ T. MCMULlaN, «Luis Cernuda y la influencia emergente de Pierre Reverdy», en D. HARris (ed.), Luis Cernuda, Madrid, Taurus, 1984, pp. 244-268; la cita en p. 246. La versión original de este artículo en inglés es: Revue de Littérature Comparée, 1 (1975), pp. $129-150$.

${ }^{61} \mathrm{Ib}$., p. 246. Explicando su propia poesía, Cernuda dice: «Lo del "equivalente correlativo" es frase muy conocida de ensayo de Eliot. Como mis libros están ya en Los Ángeles, no puedo decirle en qué ensayo ocurre, ¿quizá en Tradition and individual talent?», en F. ORTIZ (comp.), op. cit., p. 89. 
1. La nostalgia.

«Tard dans la nuit...»

La fenêtre déverse un carré bleu ${ }^{62}$

\begin{abstract}
«Va la sombra invasora»
Sólo el azul rectángulo Que vierte la ventana hacia fuera, en el tiempo misterioso resbala.
\end{abstract}

«Enciende la noche hoguera» Arquitectura huidera el dormido cielo escala.

3. La atmósfera de magia.

«Le sang.de ménage»

Et les cyprès tiennent la lune dans [leurs doigts (Ib., p. 81)

«Ingravido presente»
Y bajará la luna
A posarse en la mano.

4. La esterilidad artística.

«Tout dort»

[...] Une main avance à travers [l'ombre, le rayon, le papier sur la [table.

C'est pour prendre la lampe [...] (Ib., p. 173)
«La soledad. No se siente»
.. la luz abre su huella
(...) sólo el tiempo llena
el blanco papel vacío
«Vidrio de agua en manos de hastío»
La soledad, tras las puertas cerradas,
Abre la luz sobre el papel vacío.

5. El título del poema reverdiano «Mémoire d'homme» (p. 168) encuentra recreación imitativa en «Existo, bien lo sé»:

Soy memoria de hombre;

Quedamos redimidos de la sombra

Para no ser ya más

Que memoria de luz;

Donde yo sólo sea

Memoria de una piedra sepultada entre ortigas.

6. El estado emocional que desborda los límites inmediatos del poeta.

\author{
«Abîme» \\ [...] \\ Sous le toit la gouttière pleure \\ Et le train au loin qui criait \\ La chambre s'étendait bien plus loin \\ [que les murs [...]. (Ib., p. 110)
}

«Razón de las lágrimas»

La noche por ser triste carece de [fronteras.

Su sombra, en rebelión como la es[puma,

Rompe los muros débiles

Avergonzados de blancura 
7. La incomunicación y hostilidad de la ciudad.

«Tête perdue»

Près de moi il y a des gens qui en

«Mares escarlata»

me [gardent même pas (Ib., p. 68)

Los mares desbordados

Que atraviesan ciudades humeantes

8. El carácter contemplativo de las estrellas y el firmamento.

«Les corps ridicules des esprits» Les sprits qui se sont réfugiés derrière les étoiles regardent. (Ib., p. 67)
«Destierro»

Una luz lejos piensa

Como a través de un cielo

9. Cierta atmósfera de persecución.

«Une apparence médiocre»

Il est seul, on le croit seul. Pourtant quelque chose le suit ou peut-être quelqu'un dans la forme étrange de son ombre. (Ib., p. 23)

«Destierro»

Le abandona la noche y la aurora lo [encuentra,

Tras sus huellas la sombra tenazmente

10. La fusión del mundo de los sueños con la visión de la ciudad.

«Les pas brisés»

[...] c'est un rêve et il n'a pas de voix (Ib., p. 57)

11. La imagen aterradora de la muerte.

«Grand'route»

Et l'ombre du temps s'en irait

Le soir

Faire le tour du monde

(Ib., p. 135)
«En medio de la multitud» quise gritar, y no hallé mi voz

12. La necesidad de mantener el contacto con los aspectos básicos de la experiencia cotidiana.

«Le Gant de Crin»

Ce qui l'inquiète, c'est son âme et les rapports qui la relient, malgré tous les obstacles, au monde sensible et extérieur.
«Drama o puerta cerrada»

Sólo sabemos invocar como niños al [frío

Por miedo de irnos solos a la sombra [del tiempo

13. Ilusiones ópticas producidas por el ocaso del sol.

une palissade énorme qui montre se cacher dans l'ombre
En tiempo de crepúsculo

Cuando las desapariciones

Confunden los colores a los ojos

14. La maleza sugiere las oscuras regiones del subconsciente.

Il a laissé dans les buissons ses souvenirs et les années passées sans rien comprendre
Déjame esta voz que tengo Lo mismo que a la pampa le dejan Sus matorrales de deseo 


\section{LA INFLUENCIA DESDE LA POÉTICA}

En cambio, no importa tanto el paradigma semántico que proporciona la poesía de Reverdy, cuanto lo que Cernuda «aprende estéticamente» ${ }^{63}$. En este sentido, el poeta francés había expuesto una seriación de pautas poéticas a lo largo de su escritura ensayística que da cumplida cuenta de los principios que sustentan su poética ${ }^{64}$. Así, en lo que concierne al atractivo que pudo suponer para el Cernuda incipiente de Perfil del Aire, «la estética [...] es parte del arte. Está en el espíritu y el espíritu es el arte mismo. La estética es una armadura, y el espíritu una medida que hace posible al arte: lo sostiene, lo sitúa en la vida en lugar de dejarlo arrastrarse en ella» ${ }^{65}$. En «Self Defense» (1919), ya había dicho que «el espíritu hace la época» (ib., p. 29). Este concepto, indudablemente contrasta con la idea tradicional, la idea de raíces valeryanas de la poesía pura ${ }^{66}$,

${ }^{62}$ P. Reverdy, Les Épaves du Ciel, op. cit., p. 101.

${ }^{63}$ D. HARRIS, op. cit., p. 65.

${ }^{64}$ Un sintético y esclarecedor panorama de la poética de Reverdy, ofrece el detallado estudio de A. JimÉNEZ Millán, «La poética de Reverdy», Analecta Malacitana, VI, 1 (1983), pp. 21-40.

${ }^{65}$ P. REVERDY, «La estética y el espíritu» [1921], en Escritos para una poética, Caracas, Monte Ávila, 1977, p. 50.

${ }^{66}$ En cuanto a su origen, «la teoría de la "poésie pure" fue derivada de un ensayo de Poe, The Poetic Principle, por los simbolistas franceses, y por Baudelaire, Mallarmé y Valéry» (A. L. GEIST, La poética de la generación del 27 y las revistas literarias: de la vanguardia al compromiso (1918-1936), Barcelona, Labor, 1980, p. 119). Aunque la polémica sobre la poesía pura en Francia repercutió en los poetas españoles, la virulencia con que se desarrolló entre las posturas en liza no encuentra paralelo en sus acólitos hispánicos. Será a través de determinados autores que atendían el escenario poético del país vecino como llegarán algunos ecos de aquellas discusiones que mantenían los citados con las proposiciones estéticas de $\mathrm{H}$. Brémond, si bien con una declarada toma de partido en favor de lo sostenido por aquéllos. Éste es el caso de J. Guillén, quien en su «Carta a Fernando Vela» da cumplida cuenta de estos extremos: «Porque lo de puro, tan ambiguo, con tantas resonancias morales, empuja ya al énfasis, a la confusión y a poner en la pureza todos los "Encantos de Viernes Santo", como ha hecho el abate Brémond, cuyo punto de vista no puede ser más opuesto al de cualquier "poesía pura", como me decía hace pocas semanas el propio Valéry» (Verso y Prosa, 2 (1927), p. 2, reproducida más tarde como «Poética» en la segunda edición de la antología gerardiana, de 1934, que citamos por Gerardo DIEGo (ed.), Poesía española contemporánea (19011934), Madrid, Taurus, 1985 [1959], p. 326). Parafraseando en ciertos momentos al mismo Valéry, J. Guillén afirma que «poesía pura es matemática y es química - y nada más[...]. El mismo Valéry me lo repetía [...]. Poesía pura es todo lo que permanece en el poema después de haber eliminado todo lo que no es poesía. Pura es igual a simple, químicamente. [...] Como a lo puro lo llamo simple, me decido resueltamente por la poesía compuesta, compleja, por el poema con poesía y otras cosas humanas» (ib., p. 327), y finalmente, la relativización del concepto: «Prácticamente, con referencia a la poesía realista, o con fines sentimentales, ideológicos, morales, corriente en el mercado, 
que por extensión se convierte en proclama y reivindicación de las vanguardias. El mismo P. Valéry entendió así la poesía pura:

Que l'on puisse constituer toute une oeuvre au moyen de ces éléments si reconnaissables, si bien distincts de ceux du langage que j'ai appelé insensible, que l'on puisse, par conséquent, au moyen d'une oeuvre versifiée ou non, donner l'impression d'un système complet de rapports réciproques entre nos idées, nos images, d'une part, et nos moyens d'expression, de l'autre, système qui correspondrait particulièrement à la création d'un état émotif de l'âme, tel est en gros le problème de la poésie pure. Je dis pure au sens où le physicien parle d'eau pure. Je veux dire que la question se pose de savoir si l'on peut arriver à constituer une de ces oeuvres qui soit pure d'éléments non poétiques. J'ai toujours considéré, et je considère encore, que c'est là un objet impossible à attenidre, et que la poésie est toujours un effort pour se rapprocher de cet état purement idéal ${ }^{67}$.

Estos presupuestos, a través del tamiz orteguiano, alcanzan una elevada radicalización programática ${ }^{68}$ :

Aunque sea imposible un arte puro, no hay duda alguna de que cabe una tendencia a la purificación del arte. Esta tendencia llevará a una eliminación progresiva de los elementos humanos, demasiado humanos, que dominaban en la producción romántica y naturalista. $\mathrm{Y}$ en este proceso se llegará a un punto en que el contenido humano de la obra sea tan escaso que casi no se le vea. Entonces tendremos un objeto que sólo puede ser percibido por quien posea ese don peculiar de la sensibilidad artística. Será un arte para artistas, y no para la masa de los hombres; será un arte de casta y no demótico ${ }^{69}$.

Para Reverdy, la conexión del arte puro, o de sus principios, con el espíritu, entidad de orden subjetivo, se reafirma en la vocación innata del individuo, de forma que «es un hecho que se requiere un equilibrio entre el temperamento del artista y la estética que él se crea o a la que [se] adhiere» (ib., p. 52). Esta premisa abunda aún más en la intervención particular sobre una materia que pretende expresarse desde su más absoluta objetividad. Por ello, la contradicción alcanza dimensiones oximóricas a la vez que se presta, en su vertiente más subjetiva, a una mayor coherencia desde el acercamiento cernudiano. No se trata de una concepción aislada ni particular de Reverdy; G. Apollinaire ya había postulado esta especie de hibridación para la asepsia artística en un texto crucial para las estéti-

esta "poesía bastante pura" resulta todavía, jay!, demasiado inhumana, demasiado irrespirable y demasiado aburrida» (ib., pp. 327-328).

67 P. VALÉRY, «Poésie Pure», en Oeuvres Complètes, Paris, Gallimard, 1957, pp. 14561463, citado por J. M. RozAS, La generación del 27 desde dentro. Textos y documentos, Madrid, Istmo, $1987^{2}$, p. 179.

${ }^{68}$ En este sentido conviene tener en cuenta que «la praxis vanguardista en buena medida se funda en la revitalización revolucionaria del género teórico de la 'poética'» (P. AUllón DE HARO, op. cit., p. 103).

69 J. ORTEGA Y GASSET, La deshumanización del arte [1925], en Obras completas, Madrid, Revista de Occidente, $1962^{3}$, III, p. 359. 
cas vanguardistas, pues «considerar la pureza, es bautizar el instinto, es humanizar el arte y divinizar la personalidad» ${ }^{70}$. Mas, por si aún fuera poco, Reverdy realiza una declarada defensa de la poesía como ars imitativa: «En arte la influencia es después de todo algo perfectamente lícito» ${ }^{71}$, y sobre todo desde su función de adiestramiento técnico, la cual ha sido eludida generalmente para «convertir este arte profundo [la pintura] del que sólo se ha visto el aspecto superficial, en un arte superficial. Con esta manera deplorable de juzgar sólo se ha visto incoherencia allí donde no hubo sino búsqueda de disciplina desde el comienzo» («Sobre el Cubismo», $i b .$, pp. 10-11).

El carácter objetual de la poesía cernudiana de Perfil del Aire enlaza y puede explicarse suficientemente desde la finalidad estética enunciada por Reverdy:

Como la perspectiva es un medio de representar los objetos según su apariencia visual, hay en el cubismo medios de construir el cuadro no tomando en cuenta los objetos sino como elemento y no desde el punto de vista anecdótico. («Sobre el Cubismo», ib., p. 11)

En conclusión, existe una íntima relación entre la vida, el espíritu, la época, el individuo, por un lado, y el arte y la poesía por otro:

Estamos en una época de creación artística en que ya no se cuentan historias de manera más o menos agradable, sino que se crean obras que, al dis-

${ }^{70}$ G. APOLlinAIRE, Meditaciones estéticas. Los pintores cubistas, Madrid, Visor, 1994 [1913], p. 15. Este opúsculo es tan fundamental como lo pueda ser la figura de su autor con respecto a las vanguardias, cuya colaboración con la revista reverdyana Nord-Sud fue un hecho desde el primer número (15 de marzo de 1917), en el que el mismo Reverdy lo destaca como el mentor de las nuevas tendencias: «No hace mucho, los poetas jóvenes fueron en busca de Verlaine para sacarlo de la oscuridad. Nada tiene de asombroso que creamos llegado el momento de agruparse en torno a Guillaume Apollinaire. Él más que nadie ha trazado en la actualidad nuevas rutas, abierto nuevos horizontes. Tiene derecho a todo nuestro fervor; a toda nuestra admiración», en I. VILLALBA, M. MIRATLLES y A. F. Molina (trads.), «Guillaume Apollinaire», Hora de Poesía, op. cit., pp. 95-116; p. 96.

${ }^{71}$ P. REVERDY, «La estética y el espíritu», en Escritos para una poética, op. cit., p. 49; esta idea está provista de carácter general para el conjunto de las vanguardias desde su fomulación por el mismo G. Apollinaire (op. cit., p. 14): «La pintura se purifica, en Occidente, con esa lógica ideal que los pintores clásicos han transmitido a los de hoy como si les dieran vida». Lo que no es óbice para que, por otro lado, asevere que «el arte moderno rechaza, en general, la mayor parte de los medios de agradar utilizados por los grandes artistas de tiempos pasados» (ib., p. 17). Se advierte, por tanto, una aceptación, casi de necesidad, de la tradición artística, sólo que más bien se trata de aquellos aspectos que interesan a su objetivo, de ahí que el concepto de pureza en las artes revista un sesgo especial, ya que «este arte de la pintura pura, aunque consiga desprenderse enteramente de la pintura clásica, no provocará necesariamente la desaparición de ésta» (ib., p. 19). Tal finalidad, «su función social, es crear esa ilusión, la del prototipo» (ib., p. 25). 
tanciarse de la vida, vuelven a ésta porque tienen una existencia propia, más allá de que evoquen o reproduzcan cosas de la vida. De ahí que el Arte de hoy sea un arte de gran realidad. Pero hay que entender realidad artística y no realismo, que es el género más opuesto a lo que decimos. («Sobre el Cubismo», ib., p. 12)

Esta premisa sanciona que «la verosimilitud ya no tiene ninguna importancia, puesto que el artista lo sacrifica todo a las verdades, a las necesidades de una naturaleza superior que él supone sin descubrirla. El tema ya no importa nada o apenas nada ${ }^{72}$. Esa naturaleza superior se proyecta en una idea que en absoluto cabe identificar con la platónica clásica, sino con una cuarta dimensión: «Tal y como se presenta en la mente, desde el punto de vista plástico, la cuarta dimensión estaría engendrada por las tres medidas conocidas: configura la inmensidad del espacio eternizándose en todas las direcciones en un momento determinado. Es el espacio mismo, la dimensión del infinito; es' la que dota a los objetos de plasticidad» (ib., p. 22). Esta tendencia a «expresar la grandeza de las formas metafóricas» (ib., p. 23) conduce a que «el arte actual, sin ser emanación directa de creencias religiosas determinadas, presenta sin embargo varios rasgos del gran arte, es decir del Arte religioso» (id.).

Este distanciamiento, esta separación que a pesar de todo existe entre vida y arte, los concreta Reverdy en «ese error común debido al cual se han considerado más artísticos los temas tristes, penosos, melancólicos (en poesía), con exclusión de los alegres, cuando el caso es que el arte debe emocionar de un modo enteramente distinto al de estos medios, los cuales le son extraños, tanto unos como otros. Es liberándose de estos sentimientos como el arte se construye -mientras más libre de ellos sea, más alto y puro es» («La emoción», ib., pp. 20-21). Esta propuesta de enajenación afectiva contribuirá decisivamente a «alcanzar un arte que no pretenda imitar la vida o interpretarla» («Ensayo de estética literaria», $i b .$, p. 13). Frente a la práctica más común hasta ahora que presenta «un hecho hábilmente imaginado que, haciéndonos olvidar la vida en que estamos, puede darnos por un momento la ilusión de un fragmento de vida irreal intensa, aunque no equiparable con la vida que se quiso imitar» (ib., p. 15), Reverdy pretende que «la obra creada debe imponerse tal como es» (id.):

Porque es evidente que el arte comprendido como hasta ahora se quería que fuese comprendido, era sólo una disminución de la realidad, un parásito de la realidad, ya que sólo servía para imitarla o interpretarla. Daba una ilusión de ella que la educación y la confusión verbal terminaron haciendo llamar realidad. Así se llegó a confundir realidad de la vida y realidad artística, e insensiblemente se llegó al realismo, que pierde completamente esta última realidad y es sólo una mayor servidumbre del arte. (Ib., pp. 15-16)

${ }^{72}$ G. ApOllinaire, op. cit., p. 17. 
La finalidad, por tanto, de toda propuesta estética es «hacer algo de nada» («La emoción», ib., p. 21), si bien no se olvida, insistiendo en la imposibilidad de deshacerse del individuo, de que «por nuestra naturaleza, estamos sujetos a la creación humana con el apoyo de elementos extraídos de la vida común y de nuestra propia vida» $(i d$.$) . En cierto modo, la$ radicalidad de la sentencia genésica de Reverdy, luego atemperada, alcanza una formulación más precisa en Apollinaire, según se apreció antes, por la que el objetivo del arte se cifra en la creación de la ilusión del prototipo. Conviene destacar una diferencia de planteamiento en cuanto que Reverdy rechaza las ilusiones para dotar a cada manifestación de una entidad propia ajena a todo empleo instrumental. Con todo, la definición de Apollinaire podría explicarse desde el matiz social que explicita.

La autonomía de la obra de arte respecto al sentimentalismo y a la servidumbre hacia la vida y las cosas del mundo, su independencia respecto de la imitación de los modelos artísticos anteriores, ofrecen a toda expresión artística su identidad connatural. La vía que conduce a este extremo no es sino la de la depuración de los medios. «Los medios distinguen a las obras» ${ }^{73}$ ( La estética y el espíritu», ib., p. 50) y el principio que anima su génesis consiste en «la idea que tenemos de la posesión de sus medios» («Ensayo de estética literaria», ib., p. 16), pues «se crea gracias a los medios» («Self Defense», ib., p. 30). Para Reverdy, «si los medios siguen siendo los mismos en muchos, entonces sobreviene una repetición inútil («La estética y el espíritu», ib., p. 50). De ahí que «una estética vale lo que valen los medios que la componen («El Cubismo, poesía plástica», $i b$., p. 44). Los medios distinguen los géneros, pero también los estilos en su proyección sincrónica e histórica.

El proceso poético, para Reverdy, comienza en el despliegue cotidiano de la vida, lo que para el sujeto tiene el valor de su relación con el mundo, representada en su experiencia. Si esto supone una primera selección, casi involuntaria, «sólo la experiencia que desarrolla el tacto nos permitirá elegir elementos apropiados a nuestros medios» («La emoción», ib., p. 21). Los medios constituyen la estética, y hasta aquí todo se encuentra penetrado por el espíritu. Pero «ese tacto es el talento mismo» (id.), lo que nos devuelve a la antigua concepción de las atribuciones innatas proporcionadas por la physis.

${ }^{73}$ Esta aseveración no es posible sustraerla al planteamiento del estagirita, cuando establece la distinción de los géneros y las artes reducida a tres formas de imitación: «o por imitar con medios diversos, o por imitar objetos diversos, o por imitarlos diversamente y no del mismo modo» (p. 127), y más adelante, especifica: «Pero hay artes que usan todos los medios citados, es decir, ritmo, canto y verso, como la poesía de los ditirámbicos y la de los nomos, la tragedia y la comedia. Y se diferencian en que unas los usan todos al mismo tiempo, y otras, por partes» (ARISTóteles, Poética, ed. trilingüe de V. García Yebra, Madrid, Gredos, 1992, p. 130). 


\section{PERFIL DEL AIRE Y LE VOLEUR DE TALAN}

Hasta aquí, nuestro análisis de la influencia de Reverdy en Cernuda se ha basado en ciertos poemas de Les Épaves du Ciel, donde se integraron las composiciones contenidas en la Anthologie des Poètes Français Contemporains, esto es, «L'Sprit sort», «Le reflet dans la glace», «Fête foraine», «Fausse porte ou portrait», «Blanc et noir», «Le même numèro», «Tard dans la nuit», y «Mémoire d'homme». Sin embargo, en la antología citada también aparecen las páginas finales de Le Voleur de Talan, publicado en París en 1917. El mismo Reverdy lo consideró «su libro más autobiográfico» ${ }^{74}$, probablemente originado en su «amistad, rival a la vez que entrañable» (id.) con Max Jacob. En él «cuenta la historia de un joven de provincias que llega a la capital para triunfar como poeta, haciendo hincapié en las amistades que hace y los miedos que padece. El otro personaje importante, el mago Abel, es el propio Max Jacob» (ib., pp. 29 y 30). Su recepción no fue buena, «el libro se vende poco y se lee mal, pues se lo acusa de hermético, ya que no se conoce la historia personal que se cuenta, aunque ella por sí sola no explique la complejidad del poema» (ib., p. 30). Dependiente aún del magisterio de Max Jacob, esta novela es la segunda, después de L'Imperméable, redactada en 1916 y publicada en 1919 considerablemente modificada en la revista Sic, y tras haber compuesto también una media docena de cuentos de los que sólo dos alcanzarán edición en la revista que él mismo dirigía, Nord-Sud: Espejo... Polvo y Una noche en la llanura; los demás serán publicados con bastante posterioridad. Tras su ruptura con Max Jacob, Reverdy entiende que debe encontrar su propia manera de construir el discurso novelesco, y la encuentra en una forma especial de distribuir el texto, esto es, en lo que se ha dado en llamar «en almenas»: grupos de versos alternativamente alineados al margen izquierdo y derecho de la página.

Como se ha señalado antes, los párrafos finales de esta novela se hallaban reproducidos en la Anthologie des Poètes Français Contemporains, leída por Cernuda. De ahí nuestro interés, ya que podría iluminarnos ángulos distintos en la dilucidación de la influencia ejercida por Reverdy. Le Voleur de Talan. Roman ${ }^{75}$ consta de catorce secciones con título pero no numeradas, y las consideraciones que siguen se circunscribirán a la última de ellas. El epígrafe que le da título no es otro que el de «Il commençait

\footnotetext{
${ }^{74}$ R. LENTINI (presentación y trad.), «El ladrón de Talan de Pierre Reverdy» [secciones I y IX], Hora de Poesía, op. cit., p. 29.

${ }^{75}$ En adelante se cita por P. REVERDY, Le Voleur de Talan. Roman, Paris, Flammarion, 1967. Existe una reciente traducción española que sirve también la versión francesa en edición bilingüe: El ladrón de Talan. Novela en verso, pról. de Ph. Soupault y trad. de R. Lentini, Barcelona, Igitur, 1997.
} 
à faire / nuit quand je suis / descendu m'asseoir / près de ton ombre», lo que enseguida nos conduce al poema cernudiano de Los placeres prohibidos de título «Sentado sobre un golfo de sombra». Resulta evidente la comunidad textual existente entre ambas cláusulas discursivas en cuanto al acto de sentarse y a la presencia de la sombra. Mas para situar la compleja operación que aflora en el segmento cernudiano habría que recurrir a una densa estratificación de lecturas memoradas. Incluso, más allá de esto, plantear la posibilidad de un consciente recurso a la contaminación textual que complica con toda probabilidad el verso gongorino de la Soledad Primera «[...] en aquel incierto / golfo de sombras anunciando el puerto» (vv. 60-61) ${ }^{76}$. Por supuesto, los matices significacionales en los autores que estudiamos son algo más que simples semejanzas. El tono melancólico y hasta pesimista del poema cernudiano presenta una clara consonancia con el momento en que se localiza la acción. «Sombra» remite inexorablemente al crepúsculo vespertino, esto es, al «anochecer» del texto reverdyano. En cierto modo, el poema del sevillano resulta en una imprecación a gozar de los placeres del mundo antes que la muerte imposibilite toda oportunidad al sujeto. En otras palabras, nos enfrentamos a una reviviscencia del transitado tópico ausoniano del collige virgo rosas pero desde una perspectiva que podría entenderse más bien como homóloga a la barroca, desde la conciencia del fracaso. Efectivamente, en esta última parte de $L e$ Voleur de Talan, se produce la muerte del personaje que lo encarna, y justo cuando alcanza el puerto, como el mismo Reverdy denomina al lugar al que llega, manteniendo el paralelismo con el peregrino gongorino:

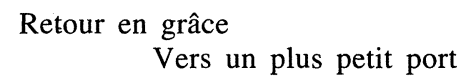

Le Voleur de Talan qui avait voulu vivre vient de mourir (p. 127)

Igualmente, el tono que envuelve estos versos últimos es el mismo que el de los cernudianos. Es más, incluso ese intento de abrazar la vida se ve asediado en los versos finales del libro, reseñados arriba, por la muerte. Esta sensación de impotencia y casi de resignación hacia una vida no realizada plenamente desde el punto de vista de su disfrute alcanza un punto de salvación en dos elementos comunes a Reverdy y Cernuda. Éste dirá en poema homónimo al verso que citamos, de la sección también mencionada, que «Los marineros son las alas del amor», sintetizando lo que el francés había ya expresado:

\footnotetext{
${ }^{76}$ L. DE GóNGORA, Soledades, ed. de R. Jammes, Madrid, Castalia, 1994, p. 209.
} 
Il pensait aux matelots qui chantent

en partant pour l'autre bout du monde

Et on reste là

Quand on sent le besoin d'avoir des ailes (p. 127)

Si éste es el final del capítulo, que acaba en noche, mas también en noche metafórica al morir el protagonista, el comienzo también se produce al tiempo que la muchedumbre de la ciudad duerme y el poeta, sin embargo, se mantiene en vela. Precisamente esta distinción entre la actividad del poeta y la del resto de la gente durante la noche se va a convertir en pilar fundamental de las secciones tercera y cuarta de La realidad y el deseo: Un río, un amor y Los placeres prohibidos. El texto de Reverdy describe la noche así:

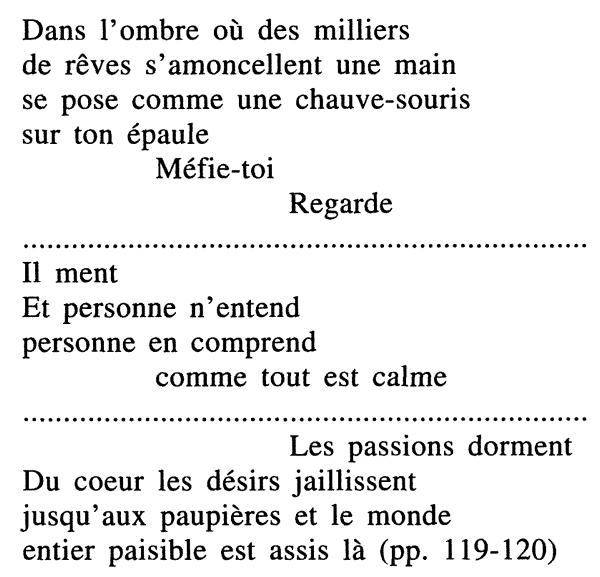

El poeta en la ciudad nocturna y solitaria da comienzo al primero de los libros surrealistas de Cernuda, «Remordimiento en traje de noche»:

Un hombre gris avanza por la calle de niebla;

No lo sospecha nadie. Es un cuerpo vacío

Es el tiempo pasado, y sus alas ahora

Entre la sombra encuentran una pálida fuerza

La muchedumbre queda perfectamente caracterizada en «Sombras blancas»:

Bajo la noche el mundo silencioso naufraga;

Bajo la noche rostros fijos, muertos, se pierden.

La figura del poeta en la oscuridad aparece en «Decidme anoche»:

Sí, la tierra está sola, bien sola con sus muertos,

$\mathrm{Al}$ acecho quizá de inerte transeúnte 
Que sin gestos arrostre su látigo nocturno;

Mas ningún cuerpo viene ciegamente soñando.

Sí, la tierra está sola; a solas canta, habla, Con una voz tan débil que no la alcanza el cielo;

Canta risas o plumas atravesando espacio

Bajo un sol calcinante reflejado en la arena.

Sus plumas moribundas van extendiendo la niebla

Para dormir en tierra un ensueño harapiento,

Ensueño de amenazas erizado de nieve,

Olvidado en el suelo, amor menospreciado.

Los ejemplos podrían multiplicarse hasta la saciedad, especialmente si se pasa a analizar los distintos matices con que esta temática es sometida a variaciones. Sin embargo, para terminar, vamos a aducir un último caso, si bien de la cuarta sección; el significado de la muchedumbre encuentra lograda expresión en «En medio de la multitud»:

Me pesaba la vida como un remordimiento; quise arrojarla de mí. Mas era imposible, porque estaba muerto y andaba entre los muertos.

Por último, es de destacar un par de casos más en los que el texto cernudiano se ve influido por los versos de Reverdy. En primer lugar la referencia al pájaro muerto:

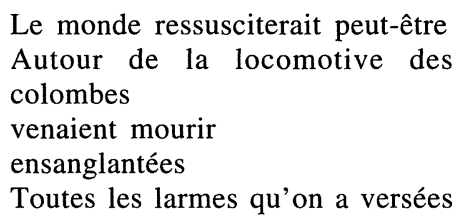

«El caso del pájaro asesinado»

Fue un pájaro quizá asesinado; Nadie sabe. Por nadie

O por alguien quizá triste en las [piedras,

En los muros del cielo.

En segundo lugar, la visión del personaje principal en tanto peregrino o viajante cuyo camino no proporciona el fin de la historia, sino la muerte del individuo. Así ocurre con el sujeto solitario de los poemas de Cernuda que tanto se prodiga en las secciones tercera y cuarta, y que muy bien podría ilustrarse con los versos ya mencionados de «Remordimiento en traje de noche» $\mathrm{y}$ «En medio de la multitud»; los versos de Reverdy son los que siguen:

Il marche le front penché les yeux baissés

et les pieds nus

El conjunto de filiaciones hasta aquí expuesto participa, como no podía ser de otra manera, de la labilidad inevitable a todas las indagaciones sobre un mundo poético tan denso y versátil como el cernudiano. Sin embargo, toda la serie de relaciones textuales explicitadas representa un 
ejemplo mínimo de cómo la piedra de toque en la exégesis textual reside en un acercamiento filológico que permita el traslado eficaz de las vaguedades explicativas a la concreción de afinidades y discrepancias. No se trata de volver a la «simple rebusca del dato concreto y el culto a la variante» ${ }^{77}$ como pretendía la crítica positivista del siglo XIX, y ante la que el mismo Azorín, entre otros, se manifestó explícitamente al denunciar que «hasta ahora, entre nosotros, la crítica histórico-literaria ha sido simplemente erudita, enumerativa; falta que sea psicológica, interpretativa, interna» ${ }^{78}$. Probablemente, la vía que concilie estos extremos partirá de la asunción del carácter hermenéutico de toda explicación, por muy objetivos que sean sus planteamientos, de forma que se considere cada texto, cada cuestión literaria, en el complejo de circunstancias especialmente textuales, artísticas y culturales que lo determinan, según la ponderación pertinente que cada manifestación requiera., Y he ahí la intervención ponderada del iudicium del filólogo - que tanto revuelo levantó al hacerlo explícito Langmann para la crítica textual, como si antes no existiera ni después se hubiera mantenido presente-, que habrá de establecer el procedimiento exegético desde la más básica configuración material del texto. Éste es un modo de entender la crítica literaria que exige, en este caso, actuar como Cernuda lo hacía respecto a sus grandes tradiciones, como lectores atentísimos a la construcción del poema, a cómo el pensamiento se hace palabra, a la vez repetida y distinta en una tarea inusitada que combina débito y creación.

77 D. Alonso, reseña a Pedro CALDERón DE LA BARCA, Autos sacramentales, ed de Á. Valbuena Prat, 2 vols., Madrid, Ediciones de La Lectura, 1926 y 1927 para cada vol., en Revista de Filología Española, 15 (1928), pp. 79-81; p. 79.

${ }^{78}$ Azorín, Clásicos y modernos [1913], en Obras completas, ed. de Á. Cruz Rueda, Madrid, Aguilar, 1975, I, p. 1138. 


\title{
RESUMEN
}

Sobre estética y poética cernudianas. Unas notas desde la lectura de Pierre Reverdy, por José Miguel Serrano de la Torre.

Este estudio consiste fundamentalmente en el análisis de la relación entre la poética cernudiana y la de P. Reverdy. Para ello se plantea en primera instancia un procedimiento historiográfico que permite descubrir las circunstancias en que se produce este contacto, entre las que cabe señalar como una de las más importantes las indicaciones de P. Salinas como maestro, en cierto modo, del 27. A continuación se exponen las relaciones entre la concepción poética de ambos autores y de los fragmentos textuales que revelan una dependencia imitativa más evidente. En este sentido, se plantean los logros analíticos de D. Harris y T. McMullan, y añadimos una serie de paralelismos deparados por el cotejo con la novela reverdyana Le Voleur de Talan.

Palabras clave: Luis Cernuda, Pierre Reverdy, Pedro Salinas, «Generación del 27», imitatio, Perfil del Aire, Les Épaves du Ciel, poesía, Vanguardia, Cubismo, poesía pura, poética, experiencia poética, magisterio, Le Voleur de Talan, intertextualidad, Filología.

\begin{abstract}
This study essentially consists on the explanation of the relationship between Cernuda's and Reverdy's poetics. In first place, a historiographical method is employed to discover the cirscunstances this contact happened. Among these ones, may be emphasized the advices given by P. Salinas as, in a special way, master of the called «generación del 27 ». Afterwards, relations between both authors poetical minds are stablished next to the textual pieces that reveal a stressed imitative dependence. In this way, are exposed the analytical finds by D. Harris and T. McMullan, and other connections are joined after the comparisons we make with the Reverdyan novel Le Voleur de Talan.
\end{abstract}

Key words: Luis Cernuda, Pierre Reverdy, Pedro Salinas, «Generación del 27», imitatio, Perfil del Aire, Les Épaves du Ciel, poetry, Avantgarde, Cubism, pure poetry, Poetics, poetical experience, teaching, Le Voleur de Talan, intertextuality, Philology. 